\title{
Structure and Magnetic Properties of Nanocrystalline $\mathrm{NiFe}_{2} \mathrm{O}_{4}$ Prepared via Precipitation Route
}

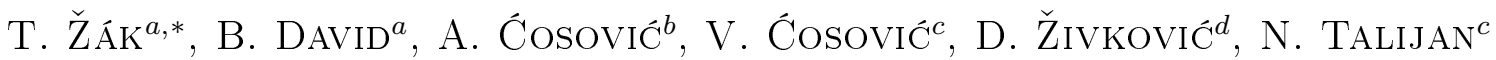 \\ ${ }^{a}$ CEITEC IPM, Institute of Physics of Materials AS CR, v.v.i., Žižkova 22, CZ-616 62 Brno, Czech Republic \\ ${ }^{b}$ Institute for Technology of Nuclear and Other Mineral Raw Materials, Franse d'Eperea 86, 11000 Belgrade, Serbia \\ ${ }^{c}$ Institute of Chemistry, Technology and Metallurgy, University of Belgrade, Njegoševa 12, 11000 Belgrade, Serbia \\ ${ }^{d}$ Technical Faculty in Bor, University of Belgrade, Vojske Jugoslavije 12, 19210 Bor, Serbia
}

\begin{abstract}
Nanocrystalline Ni-ferrite was synthesized by modified precipitation method in which soluble starch is used as dispersing agent and $\mathrm{Na}_{2} \mathrm{CO}_{3}$ as a precipitating agent. $\mathrm{NiSO}_{4} \cdot 6 \mathrm{H}_{2} \mathrm{O}$ and $\mathrm{Fe}\left(\mathrm{NO}_{3}\right)_{3} \cdot 9 \mathrm{H}_{2} \mathrm{O}$ were used as precursors for nickel and ferric oxide, respectively. The obtained nanocrystalline Ni-ferrite was analysed and discussed through structural, compositional and magnetic characterization. Formation of pure $\mathrm{NiFe}_{2} \mathrm{O}_{4}$ phase with average crystallite size of $21 \mathrm{~nm}$ has been confirmed by X-ray diffraction analysis (XRD). The determined phase composition was additionally supported by results of ${ }^{57} \mathrm{Fe}$ Mössbauer phase (MS) analysis and material's nanocrystalline structure by field emission scanning electron microscopy (FE-SEM). Thermomagnetic behaviour was studied up to $800{ }^{\circ} \mathrm{C}$. The obtained room temperature magnetic hysteresis loop, recorded by means of a vibrating sample magnetometer (VSM), exhibits characteristic "S" shape of the soft magnetic material with the measured coercivity of about $10 \mathrm{kA} / \mathrm{m}$ and the specific moment up to $40 \mathrm{Am}^{2} / \mathrm{kg}$.
\end{abstract}

DOI: $10.12693 /$ APhysPolA.126.142

PACS: 61.05.cp; 75.50.Tt; 81.07.Bc; 81.07.Wx

\section{Introduction}

Ni-ferrites are well known as one of the most commonly used soft magnetic materials. Nevertheless, recent developments in nanotechnology have broadened their already wide range of application and opened new research areas e.g. catalysis, photoelectric and nano devices, sensors, microwave devices and magnetic pigments $[1,2]$. Considering that there is a strong relation between the functional properties of Ni-ferrites and their microstructure, composition, particle and crystal sizes, the applied synthesis method plays very significant role. Hence, although synthesis of nanosized $\mathrm{NiFe}_{2} \mathrm{O}_{4}$ has been extensively studied over the years the investigation of alternative and innovative processing routes are still in progress.

\section{Experimental}

$\mathrm{NiFe}_{2} \mathrm{O}_{4}$ nanocrystalline powder was prepared by modified precipitation route with soluble starch $\left(\mathrm{C}_{6} \mathrm{H}_{10} \mathrm{O}_{5}\right)_{n}$ acting as a dispersing agent. In the first step of synthesis procedure, water solutions of analytical grade inorganic salts $\mathrm{NiSO}_{4} \cdot 6 \mathrm{H}_{2} \mathrm{O}$ and $\mathrm{Fe}\left(\mathrm{NO}_{3}\right)_{3} \cdot 9 \mathrm{H}_{2} \mathrm{O}$ were mixed in water solution of starch. Once mixed in, they break up into fine droplets confined within the polymer chains. With addition of anhydrous $\mathrm{Na}_{2} \mathrm{CO}_{3}$ (precipitation agent) an insoluble solid phase is formed. $\mathrm{Na}_{2} \mathrm{CO}_{3}$ was added to the mixture, in a quantity calculated for possible chemical reactions. Mixture was further stirred and then dried at $80{ }^{\circ} \mathrm{C}$ until solid composite was obtained. As the starch solidifies, it entraps the formed crystals in a solid organic matrix. In the final step, the

\footnotetext{
*corresponding author; e-mail: zak@ipm.cz
}

solid composite was combusted and calcinated at $900{ }^{\circ} \mathrm{C}$ for $5 \mathrm{~h}$ in order to remove the organic matrix and transform reaction products to oxides which react and give $\mathrm{NiFe}_{2} \mathrm{O}_{4}$.

Microstructure of the obtained $\mathrm{NiFe}_{2} \mathrm{O}_{4}$ powder was analyzed by field emission scanning electron microscopy (FE-SEM). Phase composition and structure were analyzed by X-ray diffraction (XRD). ${ }^{57} \mathrm{Fe}$ Mossbauer spectroscopy (MS) was used for additional phase composition analysis. Room temperature magnetic measurements were carried out by means of a Vibrating sample magnetometer (VSM) with magnetic field strength of $1000 \mathrm{kA} \cdot \mathrm{m}^{-1}$. Thermomagnetic behaviour was studied up to $800{ }^{\circ} \mathrm{C}$.

\section{Results and discussion}

The obtained FE-SEM image, given in Fig. 1, reveals fine-grained network structure of the prepared $\mathrm{NiFe}_{2} \mathrm{O}_{4}$ powder with particles of about $20 \mathrm{~nm}$.

The results of XRD analysis for the obtained powder, point to the monophase composition of pure $\mathrm{NiFe}_{2} \mathrm{O}_{4}$ phase (ICSD \#158834). The calculated crystallite size of $21 \mathrm{~nm}$ is in line with the particle size observed by FESEM, suggesting that the prepared powder consists of single crystal particles.

The results of MS analysis (Fig. 2) support the findings of the microstructural and XRD analysis, as the presented spectrum is characteristic of Ni-ferrite material. Given that the values of Mössbauer parameters i.e. isomer shift (IS) and hyperfine magnetic field $\left(\mathrm{B}_{h f}\right)$ were found to be in very good agreement with the corresponding values reported for $\mathrm{NiFe}_{2} \mathrm{O}_{4}$ [3], corresponding spectral components were assigned to tetrahedral (A) and octahedral (B) $\mathrm{Fe}^{3+}$ atom sites. The remaining set of sextets with lowered splitting represent individual $\mathrm{Fe}$ posi- 
tions with diminishing iron content in the neighbourhood of both regular sites. These iron atoms are situated on crystallite surfaces and interfaces (Fig. 2), confirming the very fine crystalline structure of the material, and pointing to a variety of crystallite sizes of $\mathrm{NiFe}_{2} \mathrm{O}_{4}$ phase. The observed doublet can be associated with presence of superparamagnetic fraction of the $\mathrm{NiFe}_{2} \mathrm{O}_{4}$ phase, having size of the order of $10-13 \mathrm{~nm}$ or less [4].

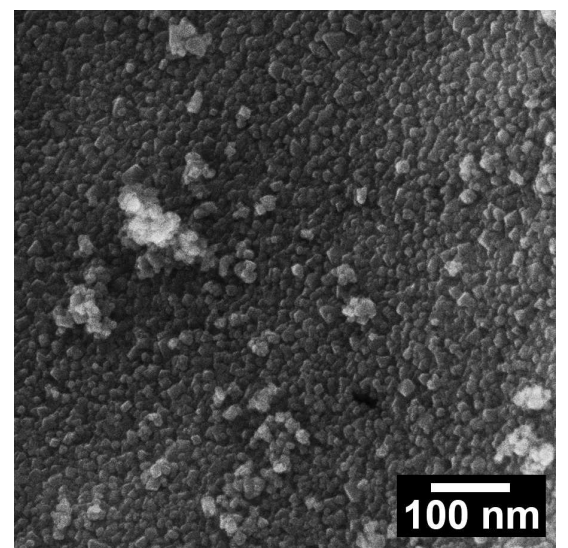

Fig. 1. Microstructure of the as-prepared $\mathrm{NiFe}_{2} \mathrm{O}_{4}$ powder.

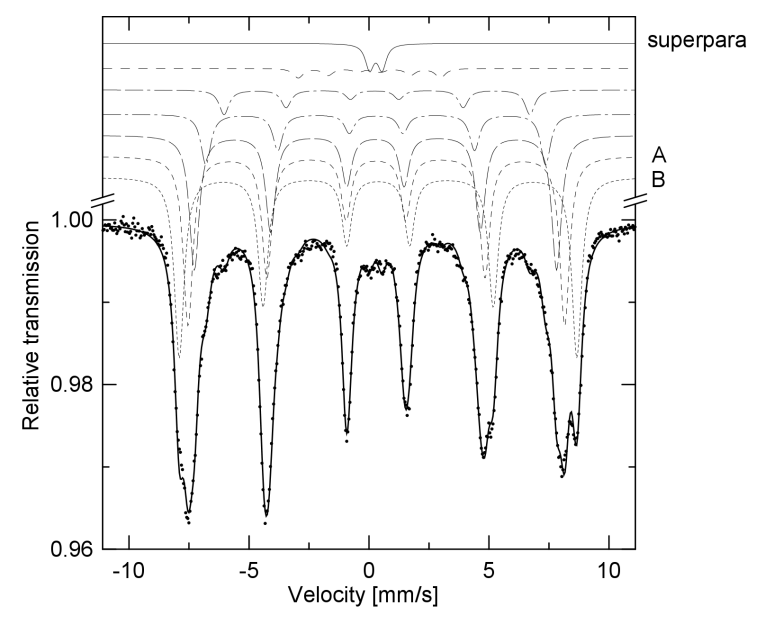

Fig. 2. Mössbauer spectrum of the obtained $\mathrm{NiFe}_{2} \mathrm{O}_{4}$ powder.

Measured values of coercivity of the order of $10 \mathrm{kA} / \mathrm{m}$ and the specific magnetic moment up to $40 \mathrm{Am}^{2} / \mathrm{kg}$ of the prepared $\mathrm{NiFe}_{2} \mathrm{O}_{4}$ powder at room temperature are included to the range expected for this type of material.

The recorded thermomagnetic curve, presented in Fig. 3, illustrates noticeable difference in the net magnetic moment of the material before and after thermal treatment. The observed behaviour is expected and can be ascribed to fieldcooling process. In addition, it is possible that some of the remaining defects and strains were removed by heat treatment and more ordered structure with larger crystals was obtained.

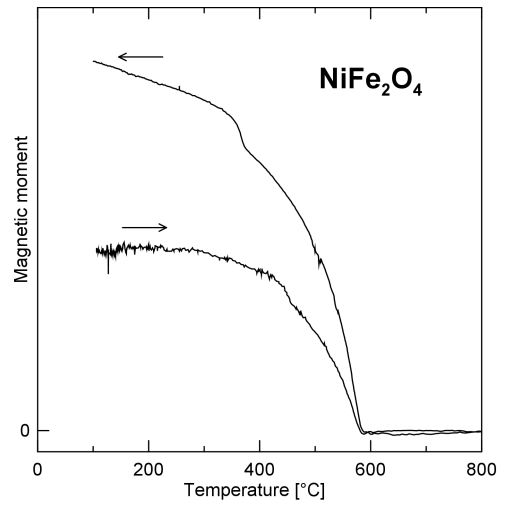

Fig. 3. Thermomagnetic curve of the $\mathrm{NiFe}_{2} \mathrm{O}_{4}$ powder.

It can be reasonably assumed that the influence of heating during thermomagnetic measurements would be reduced, if longer calcination time was applied.

\section{Conclusions}

The monophase nanocrystalline $\mathrm{NiFe}_{2} \mathrm{O}_{4}$ powder consisting of essentially single crystal particles with size of about $20 \mathrm{~nm}$ was successfully prepared by presented modified precipitation method. The results of magnetic measurements and the recorded thermomagnetic curves illustrate anticipated magnetic behaviour for this type of material. The presented synthesis method is easy and inexpensive and, unlike sonochemical [5], hydrothermal [2] or plasma route, it doesn't require any additional and expensive equipment. On the other hand, it yields material with much better uniformity of particle size than conventional coprecipitation from solution [6] or solid state reaction.

\section{Acknowledgments}

The authors acknowledge support of the Grant Agency of the Czech Republic by grant Nr. GAP108/11/1350 and of the Ministry of Education, Science and Technological Development of the Republic of Serbia (Projects OI 172037 and TR 34023). This work was realized in CEITEC- Central European Institute of Technology supported by the project CZ.1.05/1.1.00/02.0068 financed from European Regional Development Fund.

\section{References}

[1] S.L. Darshane, S.S. Suryavanshi, I.S. Mulla, Ceram. Int. 35, 1793 (2009).

[2] K. Nejati, R. Zabihi, Chem. Cent. J. 6, 23 (2012).

[3] J. Jacob, M.A. Khadar, J. Appl. Phys. 107, 114310 (2010).

[4] T. Komatsu, N. Soga, J. Appl. Phys. 51, 601 (1980).

[5] K.V.P.M. Shafi, Y. Koltypin, A. Gedanken, R. Prozorov, J. Balogh, J. Lendvai, I. Felner, J. Phys. Chem. B 101, 6409 (1997).

[6] R. Dehghan, S.A. Seyyed Ebrahimi, A. Badiei, J. Non-Cryst. Solids 354, 5186 (2008). 